absenoe of pulmonary affection and dropsy, that you will ascertain the true nature of the disease. You may be quite right in saying that the case is one of nervous irritation, and yet the person after a time may have organic disease of the heart, because when the heart has been labouring under morbid irritability for a length of time, it is very possible for one part to give way, and to have organic disense set up. This man had pricking pans over the heart, which is a common symptom in nervous palpitation of that organ. There is nothing dangerous in this particular symptom, but the pricking pains are sometimes excessively troublesome. That this has not any-thing to do with organic disease of the heart 1 am quite certain, because, many years ago, $I$ noticed it over and over again in persons who are now perfectly well. The treatment in the case of this man consisted in the local application of leeches over the region of the heart, in keeping him very quiet, and in keeping his bowels open. Upon this very simple plan he speedily got so much better, that it was not worth while for him to stay any longer in the hospital.

CEREBRAI, DISEASE.

During the past week two deaths occurred, the one from phthisis, chronic peripneumony, and cbronic pleuritis, in a man; the other in a woman from epilepsy, but whom I never saw. She was admitted one day after my visit, and it was represented that she had had a fit of epilepsy in the street; that she had been insensible, had been couvulsed, had foamed at the mouth, and had bitten her tongue. After being put to bed she came to herself, and was sitting up, nothing having been given to her but a dose of aperient medicine, and she said that she then had nothing the matter with her. While, however, she was sitting up in bed, she fell back, I understand, and died. On opening the body, the cristi galli of the ethmoid bone was carious, and the dura mater, where it was attached to this part, had become of great thickness and hardness. The corresponding part of the brain on one side, that is, the inferior part of the antejior lobe on one side, was thoroughly softened. Her history was not known, and $I$ cannot tell whether she had had epileptic fits before; it appeared that there was no paralysis, for she talked and moved her extremities very well, and did not complain of any-thing after the fit was over. 'The softening of the brain most probably had taken place in consequence of the disease of the dura mater and the ethmoid bone. I presume the part of the brain next the diseased membrane and bone had become diseased first, because when I have seen caries of the temporal bone, which $I$ have more than once in disease of the ear, the brain which was nearest to it likewise became diseased. With respect to the sudden cause of death : The left ventricle of the heart was not found empty as is usual, but filled with blood; it was not contracted at the time of death, and it is probable that the heart suddenly ceased to act. There was no disease whatever found in the heart. I presume the affection in this case must have been sympathetic, that the state of the brain must have operated upon the heart, and caused it suddenly to stop.

\section{OBSTETRIC AUSCULTATION.}

\section{Reply of Dr. Kennedy to Dr. Nagle.}

\section{To the Editor of THE LANCET.}

SiR,-I confess I felt somewhat surprised on reading a paper in your publication of the 18th inst., on obstetric auscultation, purporting to be written by a gentleman signing himself David C. E. Nagle, A.M., M.D., T.C.D. How this gentleman could have so grossly (I regret being obliged to use the expression) misrepresented the observations and facts set forth in a paper which I some time since published in the fifth volume of the Dublia Hospital Reports, I am at a loss to conceive. That his doing so could not, however, have arisen from his not understanding $m e$ is, I fear, but too evident; as it certainly required more ingenuity to misconstrue, and more art to pervert facts and statements as he has done, than could possibly be necessary to comprehend them. I should therefore deem a lengthened refutation of his paper not only unnecessary, but unbecoming, and shall merely point out a few of his most palpable misstatements, and beg to refer those who may feel interested in the subject, to the paper which I have already published. He asserts (pages 396 and Sy9) that I, with Dr. Ferguson, assume the " dangerous theory" that the placental sound should be considered an unquestionable test of impregnation; this I deny, these are my expressions :"The placental soufflet (taken in conjunction with the other symptoms of pregnancy) will tend much to strengthen the opinion of the presence of this state. The co-existence of the foetal pulsation with the souffet of course decides the question, but with regard to the latter taken separately, I will go so far as to say, that were all the other symptoms of pregnancy absent, and that this could be distinctly perceived, I should at least withhold my opinion until a sufficient time had elapsed to place the matter beyond a doubt." See Dublin Hos. 
pital Reports, vol. v., page 258-9 ; see also pages 255 and 257 , where such " dangerons theory" is not only disclaimed bit actually condemned. Again he advances, page 398, "That persons, if influenced by my theory, as he styles it, respecting the guality of the souflet affording a sure indication of the life or death of a fotus ' in utero,' would be liable to fall into very serious and egregious errors." That I support any such theory or hold any such opinion as this, I must again in the most unqualified terms deny; that I am fully justified in doing sn, will appear from the following, which are my words, when treat. ing of this alteration in the character of the sound, Hospital Reports, page "269:-_"The placental sound, either by ceasing altogether after having been previously heard, or having its character altered, from the continuous murmur with its lengthy sibilous termination, to an abrupt, defined, and much shorter sound, together with the impossibility of de. tecting the fotal heart's action, particularly if such has been before observed, places the child's death beyond a doult." "Why was the concluding portion of this quotation so cautiously, so unfairly suppressed? It was that he might give a "case" in which, though the foetus was putrid, he heard a murmur, prolonged and by no means "abrupt;" evidently insinuating that I deny the possibility of the occurrence of such a case; and he adduces it triumphant$\mathrm{ly}$, and "as furnishing him with a powerful argument against the quality of the murmur being a test indicative of the life or death of the foetus in utero." Here is the "suppressio veri" coupled, as it usually is, with the "assertio falsi," for I have given a case (page 250) where the sound was not "abrupt," although the fotus was dead, and $I$ also mention having observed such, where the fotus exhibited marks of having been dead for weeks. With these facts staring him in the face, he asserts, with what justice I leave to you and your readers to determine, that I consider the quality of the souphet as affording a sure indication of the life or death of the fotus in utero. With regard to his discovery (page 398) that a placenta is not necessary for the pro. duction of murmur such as we ordinarily hear in the advanced stages of utero-gestation, and the inference he would draw of my inaccuracy, I beg to refer the reader to a fact, of which, however it may suit $\mathrm{Mr}$. Nagle's views to appear so, he can scarcely be ignorant, namely, that I have already stated, withont any disguise (page 266), "a case where a sound resembling the souflet from a morbid cause (a considerably enlarged liver) was observable;" and also mention. ed (page 265) that those unacquainted with the stethoscope may be deceived by other sounds, from their resemblance to the pla. cental soufflet, several of which $I$ instanced. So much for misstatements and suppressions with regard to myself. I shall now notice, very briefly, a few of those general statements which are so palpably opposed to fact, that I should deem myself culpable in pass. ing them over without some remark. He says that the "bellows sound (or souflet) is heard in ninety-nine cases out of every hundred, as well on one side as on the other, in the same patient;" now, although I admit, and have mentioned the fact of its being occasionally heard on both sides in the same patient, I have no hesitation in stating as far as my experience goes, the above pro. portion is most enormously exaggerated. It (the bellows sound) 'may, I admit, says he, “be masked in some degree by the pulsations of the fœtal heart." Ridiculous! Can the fotal pulsation "mask" a sound at least ten times louder than itself? The assertion "that he was never able to trace it (the soufflet) across the anterior surface of the abdominal parietes in an uninterrupted course," may be perfectly true, but if he means that because he cannot hear it, it cannot be heard there by others, I set it down as of a piece with those already men. tioned, and 1 doubt whether he is really capable of recognising the phenomenon of which he treats. "Or ever," he adds, "to detect it under the mesial line, except when it arose from the "epigastric arteries." What degree of credit will be attached to the reasonings of a person who displays such ignorance of anatomy? I will venture to say that the merest tyro at the profession could have taught him that in no case do the " epigastric arteries lie under the mesial line;" and that in the abdomen, distended as it is in utero-gestation, each of these arteries lies from four to six inches distant from this line. Again, he speaks of the "sound being traced upwards and forwards towards the mesial line, in the course, as it were, of the trunks of the lateral uterine arteries." The trunk of the lateral uterine artery upwards and forwards and lowards the mesial line!! This is indeed "as it were," but not " as it is." If this gentleman had rested satisfied, merely with adopting views and opinions grounded on such data, however incorrect and absurd, and had his positions been supported by inaccuracies and discrepancies more palpably striking than his paper exhibits throughout ; it should have remained uncommented on by me, as such productions generally find their own level. I would, however, and with justice, have been to blame as well upon my own account as on that of the profession generally, had I allowed such a tissue of misrepresentation to remain uncontradicted. Having now done so, I must decline taking 
any further notice of his observations or ter mind could never deliberately conde. entering into any discussion with him on scend to resort to sophistry in his laudable the subject. With regard to Dr. Clinton, efforts for the establishment of so grand and whom be endeavours to identify with him- useful a principle in diagnosis. "The only self in his views and statements, I confess arteries," he says, "in which the sound in the only way in which $I$ can reconcile to myself the idea that he ever sanctioned the publication of such a paper, supported by his name (if he really did so), is that he unthinkingly entrusted himself in the hands of the writer of this paper, and acquiesced in his views without taking upon himself to inquire in to the subject, and certainly without having read my paper which his name has been brought forward to overthrow, as, uuless my opinion of this gentleman shall become altered, I cannot bring myself to imagine that he would wilfully have countenanced so much misrepresentation and ignorance.

I am, sir,

Your obedient servant, Evory KenNedY.

Lying-In Hospital, Dublin. question can be supposed to be produced, are the hypogastric, iliac, and uterine; if the two first were the site of it, we ought to hear it on both sides of the uterus at once, or alternately, which is not the case."

Now, with all possible deference for his opinion, I have proved, and I hope saticfactorily, that it is the case-that we do hear it on both sides of the uterus at once, or alternately; and of this any one, who has the tact of examining adequately, can easily satisfy himself. I have, indeed, seldom failed in finding it on both sides at once, exactly in front of the superior antericr spinous process of the ilium, opposite which, nearly, the uterine arteries are given off by the internal iliacs. I would take the liberty of putting the argument thus. If the two first were the site of the murmur, we ought to hear it on both sides at once, or alternately: but we can so hear it; and I ON THE USE OF

\title{
THE STETHOSCOPE
}

IN THE DETECTION OF PREGNANCX, \&C.

\author{
$B y$ David C.E. Nagle, A.M., M.B., \\ Trinity College, Dublin.
}

(Concluded from page 400.)

Aware of the almost unlimited degree of confidence which medical men are apt to repose in the opinions of Laennec, I apprehend that his arguments on the controverted question, "What is the site of the soufflet?" will be deemed by many entitled to very respectful consideration, notwithstanding his want of experience in the study of the phenomena afforded by gestation. To those arguments I shall now take leave to direct the attention of the reader; and whilst $I$ am endeavouring to point out their fallacy and insufficiency, I shall at the same time be submitting to the profession my own views of the matter, without, however, expecting more attention to them than the proofs I may adduce will warrant the practitioner in considering them entitled to.

Laennec scientifically reduces the question into the form of a disjunctive proposition, which, however, he does not render sufficiently adequate or comprehensive. He is, besides, infelicitous in his mode of arguing, from the remotion of all the parts but one to the position of that one. This infelicity we must attribute to his inexperience in the study of obstetric auscultation, and not, by any means, to either a deficiency of talent or a want of candour; for his mas-

No. 584. therefore respectfully submit, that we are warranted, even by his own mode of reasoning, to conclude, that the two first may be the site of the soufflet. The legitimacy, at least, of this inference, no one, I believe, will be disposed to question. 'The next part of his disjunctive proposition he thus expresses:- "If all the uterine arteries yield it, we ought then to hear it in different parts, and several at the same time." As he does not conclude the argument, I shall endeavour to do so; and, I think, it will be fairly expressed in the following manner. If all the uterine arteries yield it, we ought then to hear it at once over every part of the uterus : but I am horne out by experience when $I$ assert, that we cannot, at any time, hear it over every part of the uterus at once; and, therefore, it may be fairly inferred, that all the uterine arteries cannot be the site of the murmur. Laennec comes to the following conclusion:- "What seems to me most probable is, that it exists in the chief artery distributed to the placenta." The incorrectness of this opinion I shall endeavour to prove by the following mode of stating my objections.

If the soufflet exists in that part alone of the chief artery which is distributed to the placenta, we can have it only where there is, or lately has been, a placenta. But Corrigan's case proves the certainty of its existence where there is, or lately has been, no placenta; and, therefore, I feel that I am justified in drawing this inference, that it does not exist in THAT part of the artery which is distributed to the placenta. Now, let us consider if it can have its proper site in the trunk of that vessel. Well, if it

$$
\text { K I }
$$

